\title{
Dar o peixe ou ensinar a pescar? O empoderamento como prática de inovação social em uma organização da sociedade civil
}

\author{
THAís Teles Firmino ${ }^{1}$ \\ AndRÉ Gustavo CaRvalho Machado ${ }^{1}$ \\ ${ }^{1}$ Universidade Federal da Paraíba / Departamento de Administração, JoÃo Pessoa - PB, Brasil
}

\begin{abstract}
Resumo
O objetivo geral deste artigo foi analisar o empoderamento como prática de inovação social em uma organização da sociedade civil (OSC) nordestina. Assim sendo, selecionamos como exemplo de prática de inovação social o empoderamento de crianças e adolescentes vulneráveis socialmente. Para tanto, lançamos mão de entrevistas com funcionários da OSC, alunos, ex-alunos e familiares, observações participantes, fotos, vídeos e documentos, baseando-nos nos direcionamentos etnometodológicos. Neste contexto, foi expressivo descobrir que, além do desenvolvimento do poder pessoal, os alunos matriculados nas atividades da OSC tornavam-se multiplicadores dos conhecimentos adquiridos, contribuindo para o crescimento das pessoas de sua convivência. Esta prática se modifica ao longo do tempo pelas próprias ações das crianças e adolescentes, acompanhando seu processo de desenvolvimento pessoal, como também pelo mapeamento de necessidades das comunidades e planejamento das atividades que a OSC realiza. Ademais, este artigo contribui de diversas maneiras, em especial no que se refere ao delineamento de uma concepção teórica integrativa e à investigação de como a prática se desenvolve e se legitima em um dado contexto, evidenciando seus gatilhos e meios de materialização.
\end{abstract}

Palavras-chave: Inovação social. Prática. Empoderamento. OSC. Vulnerabilidade social.

\section{Give a fish or teach to fish? Empowerment as a practice of social innovation in a civil society organization}

\begin{abstract}
This article aims to analyze empowerment as a practice of social innovation in a civil society organization (CSO) working with vulnerable children and adolescents in the Northeast of Brazil. The study adopted an ethnometodological approach, using interviews with the organization's staff, children and adolescents that participate or participated in the project, and their families. In addition, the study used participant observation, photos, videos, and document analysis. The results show that besides the individuals empowerment, the participants of the project became multipliers of the acquired knowledge, contributing to the development of other people in their networks. The social innovation practice analyzed has changed over time based on the action and demands of the children and adolescents involved, following their personal development process. Also, the practice is improved based on the CSO's planning and work of mapping community needs. This article contributes to delineate an integrative theoretical conception, helping to investigate how the practice develops over time and is legitimized in the context, evidencing its founding elements and means of materialization.
\end{abstract}

Keywords: Social innovation. Practice. Empowerment. CSO. Social vulnerability.

¿Dar un pescado o enseñar a pescar? El empoderamiento como práctica de innovación social en una organización de la sociedad civil

\section{Resumen}

El objetivo general de este artículo fue analizar el empoderamiento como práctica de innovación social en una organización de la sociedad civil (OSC) del nordeste de Brasil. Así pues, seleccionamos como ejemplo de práctica de innovación social el empoderamiento de niños y adolescentes vulnerables socialmente. Para ello, recurrimos a entrevistas con empleados de la OSC, alumnos, exalumnos y familiares, observaciones participantes, fotos, videos y documentos, basándonos en las directrices etnometodológicas. En este contexto, fue significativo descubrir que, además del desarrollo del poder personal, los alumnos matriculados en las actividades de la OSC se convertían en multiplicadores de los conocimientos adquiridos, contribuyendo al crecimiento de las personas con las que convivían. Esta práctica se modifica a lo largo del tiempo a partir de las propias acciones de los niños y adolescentes, acompañando su proceso de desarrollo personal, así como a partir del mapeo de necesidades de las comunidades y planificación de las actividades que la OSC realiza. Además, este artículo contribuye de diversas maneras, en especial en lo que se refiere al delineamiento de una concepción teórica integrativa y a la investigación de cómo la práctica se desarrolla y legitima en un contexto dado, evidenciando sus desencadenantes y medios de materialización.

Palabras clave: Innovación social. Práctica. Empoderamiento. OSC. Vulnerabilidad social. 


\section{ASPECTOS INTRODUTÓRIOS}

O Brasil ocupa a 79a posição no ranking mundial de desenvolvimento humano (UNPD, 2016) e se mantém entre os países mais desiguais da América Latina (IBGE, 2015), apresentando desafios em diversas áreas, tais como: saúde, educação, moradia, segurança, etnia, gênero, distribuição de renda e trabalho. Nessa conjuntura, percebemos distorções que progridem ao longo do tempo e ocasionam a perpetuação de uma condição de exclusão e vulnerabilidade social, o que pode levar à discriminação e ao isolamento dos indivíduos (COSTA e MARGUTI, 2015). Esse cenário se reflete nas pesquisas mais recentes, posicionando o país em um nível médio de vulnerabilidade social (COSTA e MARGUTI, 2015). Na contramão do índice nacional, como chamam a atenção estes últimos autores, as regiões Norte e Nordeste apresentam as maiores concentrações de municípios com faixas muito altas de vulnerabilidade, evidenciando ainda mais as desigualdades.

Nesse panorama, a situação das crianças e adolescentes merece atenção, pois as experiências presentes e futuras de privação impactam em seu desenvolvimento humano e na transição para a vida adulta (COSTA e MARGUTI, 2015). Aliado a isso, elas também representam a expectativa de mudança dessas condições na busca por um país mais justo. Todavia, apesar da promulgação do Estatuto da Criança e do Adolescente (ECA) em 1990, seus fundamentos ainda precisam ser compreendidos e praticados nos municípios brasileiros. Como exemplo disso, houve o registro de mais de 182 mil denúncias de violações de direitos contra crianças e adolescentes (violência psicológica, física, sexual, negligência, entre outros) em 2014 (FUNDAÇÃO ABRINQ, 2016). Na tentativa de modificar tal realidade, entre outras ações, o Governo Federal tem investido em parcerias com Organizações da Sociedade Civil (OSCS) no intuito de fortalecer a atuação da esfera pública frente às necessidades locais.

Sob a perspectiva acadêmica, em virtude das referidas desigualdades e iniciativas, visando minimizá-las, emerge um amplo campo de estudos e prática da Inovação Social (IS). Nesse contexto, Van der Have e Rubalcaba (2016) identificaram que as publicações a respeito desse assunto têm apresentado franco crescimento desde 2003. A explicação para esse crescente interesse parece estar no número cada vez maior de problemas sociais, econômicos e ambientais, bem como nas mudanças da sociedade e cultura (MURRAY, MULGAN e CAULIER-GRICE, 2008; CAJAIBA-SANTANA, 2014). Como consequência da existência dessas demandas em cenários diversos, a inovação social é interdisciplinar, abrigando abordagens de várias áreas de conhecimento que atuam por ângulos distintos.

Constatamos também um conjunto de lacunas provocado pela necessidade de maior clareza conceitual, fragilidade das perspectivas teóricas e incompreensão do processo de inovação social (HOWALDT e SCHWARZ, 2010; VAN DER HAVE e RUBALCABA, 2016, SILVEIRA e ZILBER, 2017), bem como pela incipiência das pesquisas sobre o tema no Brasil (AGOSTINI, VIEIRA, TONDOLO et al., 2017). Adicionalmente, a literatura destaca que a compreensão da temática requer novas bases teóricas, até mesmo para a exploração dos vínculos entre inovação e mudança social (HOWALDT, DOMANSKI e KALETKA, 2016; AGOSTINI, VIEIRA, TONDOLO et al., 2017; SILVEIRA e ZILBER, 2017).

Em vista disso, adotamos nesta pesquisa o olhar da inovação social como uma prática, reconhecendo seu processo como um fenômeno construído pelas interações cotidianas entre os envolvidos. Portanto, neste artigo, as inovações sociais são "[...] novas práticas sociais criadas a partir de ações coletivas, intencionais e orientadas a um objetivo, visando à mudança social por meio da reconfiguração de como os objetivos são alcançados" (CAJAIBA-SANTANA, 2014, p. 44). As práticas sociais, por sua vez, são atividades (conjuntos de ações) humanas organizadas (SCHATZKI, 2001). Cada atividade que constitui a prática envolve dizeres (ações básicas que dizem algo sobre alguma coisa) e fazeres (ações básicas executadas pelas pessoas com os seus corpos) inteligíveis em um dado contexto (SCHATZKI, 2001). De acordo com esse raciocínio, a inovação social tem por finalidade a mudança no comportamento coletivo, manifestando-se por meio de novas práticas oriundas de um processo colaborativo e contínuo.

Delineamos nosso problema de pesquisa considerando a relevância de estudos desta natureza em regiões com nítidos problemas e desafios sociais (IWAMOTO e CANÇADO, 2016), o papel das OSCs em conjunto com outras organizações na minimização desse cenário e da incompreensão de como cada ator contribui no desenvolvimento das inovações (AGOSTINI, VIEIRA, TONDOLO et al., 2017). Partindo do princípio da indiferença etnometodológica (BISPO e GODOY, 2014), isto é, não definindo uma prática a priori, o empoderamento surgiu após imersão no campo, de forma emergente, sem uma prévia intenção. Com isso, norteamo-nos pela seguinte questão: como ocorre o desenvolvimento do empoderamento como prática de inovação social em uma organização da sociedade civil nordestina que atua na inclusão de crianças e adolescentes de comunidades carentes? 
O empoderamento, por sua vez, é um processo de busca por autonomia e autodeterminação, em que se desenvolve um senso de poder pessoal, o que não exclui a possibilidade de o indivíduo ser ajudado nessa trajetória por profissionais ou agentes externos (KLEBA e WENDAUSEN, 2009; GONZALEZ-MENA, 2015). Portanto nosso objetivo principal neste artigo é analisar o empoderamento como prática de inovação social em uma organização da sociedade civil nordestina.

Os resultados desta pesquisa contribuem para avançar a temática da inovação social, por adotar uma nova base teórica de compreensão das inovações (HOWALDT, DOMANSKI e KALETKA, 2016; AGOSTINI, VIEIRA, TONDOLO et al., 2017) e analisar longitudinalmente a inovação e seus efeitos (AYOB, TEASDALE e FAGAN, 2016) em uma perspectiva comparativa de uma situação anterior e outra posterior em um dado contexto (MAURER e SILVA, 2015). Ademais, do ponto de vista metodológico, este trabalho confirma o potencial da adoção da etnometodologia garfinkeliana como método a ser empregado nos estudos organizacionais (ADAMOGLU DE OLIVEIRA e MONTENEGRO, 2012).

Após esta introdução, delineamos os direcionamentos teóricos que embasaram nossa compreensão do desenvolvimento de práticas de inovação social. Em seguida, descrevemos os procedimentos metodológicos. Logo depois, discutimos os resultados e apresentamos as conclusões.

\section{DIRECIONAMENTOS TEÓRICOS}

Em virtude do crescente aumento de necessidades sociais, os estudos em inovação social têm recebido maior atenção, levando a avanços para além das fronteiras acadêmicas (SILVA e BITENCOURT, 2016). Além das expressivas contribuições conceituais que têm sido realizadas por centros de pesquisa de universidades, esforços têm sido empreendidos com vistas ao desenvolvimento de políticas públicas, prática e pesquisa de inovação social, a exemplo de: The Young Foundation, Nesta e European Comission no Reino Unido e a OECD em nível mundial (POL e VILLE, 2009; SILVA e BITENCOURT, 2016).

Por meio da revisão da literatura, percebemos que os estudos sobre inovação social são marcados pela miríade de trabalhos provenientes de visões distintas, o que ocasiona ambiguidade conceitual e delimitações teóricas inevidentes (CAJAIBASANTANA, 2014; PHILLIPS, LEE, JAMES et al., 2015; VAN DER HAVE e RUBALCABA, 2016). Identificamos que um primeiro passo para orientação dentro do tema é refletir sobre os significados dos termos "inovação" e "social" que constituem o conceito. A inovação reside: na percepção de novidade para os envolvidos no processo; no seu contexto; ou ainda na forma de aplicação da iniciativa, por exemplo: o acesso à internet não é uma inovação para um grande empresário, porém pode ser para uma comunidade indígena em isolamento. Quanto ao social, certos autores (MURRAY, MULGAN e CAULIER-GRICE, 2008; PHILLS, DEIGLMEIER e MILLER, 2008) entendem que o termo abrange desafios sociais amplos e globais, tais como: as problemáticas advindas de mudanças climáticas.

Enquanto isso, outros autores (MOULAERT, MARTINELLI, SWYNGEDOUW et al. 2005; MONTGOMERY, 2016) preocupam-se com questões mais específicas de grupos em uma perspectiva de desenvolvimento local, como exemplo a exclusão social (MAURER e SILVA, 2015; VAN DER HAVE e RUBALCABA, 2016), sendo esta a percepção mais difundida. Há, ainda, uma corrente de autores (CAJAIBA-SANTANA, 2014; HOWALDT, KOPP e SCHWARZ, 2015) que trata as inovações sociais como prática e, por esta razão, o "social" aparece pela ação coletiva e intencional com vistas a mudanças em quaisquer estratos da sociedade, não necessariamente para atender demandas de grupos marginalizados ou situações globais desafiadoras. Por nos norteamos pelo olhar da inovação social como uma prática, entendemos que a unidade de análise deve ser a própria prática, o que significa um enfoque empírico nos processos de mudança e reconhecimento social dos conjuntos de atividades. Ao mesmo tempo, identificamos nos estudos uma preocupação com o quanto as inovações sociais podem atender às demandas das minorias e, principalmente, empoderar.

Nesta ênfase em desenvolvimento local, existem abordagens mais orientadas aos resultados (MULGAN, TUCKER, ALI et al., 2007; POL e VILLE, 2009), com enfoque em alternativas e soluções geradoras de mudança social, isto é, as formas que a inovação social assume, seus resultados. Segundo Moulaert, Martinelli, Swyngedouw et al. (2005) e Murray, Mulgan e Caulier-Grice (2008), suas formas são várias, dentre elas: produtos, serviços, modelos, metodologias e formas de governança. Há também as abordagens mais orientadas ao processo (MOULAERT, MARTINELLI, SWYNGEDOUW et al. 2005; MONTGOMERY, 2016), que visam à compreensão da mudança social enfocando a transformação das práticas geradoras da situação de exclusão e vulnerabilidade social.

Neste contexto, alguns autores (MOULAERT, MARTINELLI, SWYNGEDOUW et al. 2005; ANDRÉ e ABREU, 2006; MONTGOMERY, 2016) argumentam que as abordagens orientadas aos resultados são meios paliativos de responder às demandas sociais, 
pois as inovações nesse âmbito muitas vezes colocam os sujeitos em uma condição de consumidor, deixando-os dependentes de agentes externos. Segundo tais autores, o objetivo deve ser empoderar os sujeitos e, para tanto, integrar os grupos-alvo no processo, aumentando sua participação (IWAMOTO e CANÇADO, 2016; MONTGOMERY, 2016). Com esse raciocínio, as abordagens orientadas ao processo se preocupam com o potencial empoderador das inovações, que, por sua vez, conferem maior durabilidade aos resultados.

Em inovação social, o empoderamento é entendido como maior acesso a recursos que permitam a satisfação de necessidades humanas, em conjunto com uma maior participação social e política (MOULAERT, MARTINELLI, SWYNGEDOUW et al. 2005; ANDRÉ e ABREU, 2006; MONTGOMERY, 2016). Em virtude do caso estudado, optamos por entender o empoderamento como um processo de busca por autonomia e autodeterminação, em que se desenvolve um senso de poder pessoal, o que não exclui a possibilidade de o indivíduo ser ajudado nessa trajetória por profissionais ou agentes externos (KLEBA e WENDAUSEN, 2009; GONZALEZ-MENA, 2015). Percebemos que, ao tratar de inovações com vistas ao enfrentamento de desigualdades sociais, estas podem ser compreendidas analogicamente ao dilema para solução da pobreza: dar o peixe ou ensinar a pescar? Com esta expressão, buscamos evidenciar a utilidade das inovações estudadas pelas abordagens orientadas aos resultados (dar o peixe) na transformação das práticas que perpetuam a situação de exclusão e vulnerabilidade social (ensinar a pescar).

Por exemplo: pessoas que estão em situação precária de moradia e passando fome podem ser bastante ajudadas por um empreendimento social que viabilize alimentação e moradia adequadas a elas (dar o peixe). Tendo suas necessidades básicas atendidas, esse mesmo grupo pode participar de capacitações visando à sua inserção no mercado de trabalho (ensinar a pescar). Isso implica pensar a inovação social como um processo contínuo, de modo que ao longo do tempo ela pode ter formas diferentes de acordo com o contexto, produzindo resultados mais paliativos e/ou dependentes de agentes externos e, em outros momentos, mais duradouros por meio do desenvolvimento do senso de poder pessoal dos sujeitos. Estes últimos são mais difíceis de difundir, uma vez que envolvem transformações pessoais carregadas de sentidos e significados muito próprios dos grupos.

Ao mesmo tempo, assim como todas as práticas, as inovações são tácitas e simbólicas em grande medida (BISPO, 2013). Desse ponto de vista, analisar o processo de inovação social envolve a "[...] compreensão de como são produzidas e reproduzidas as formas de organizar dos atores sociais" (BISPO, 2013, p. 18). Portanto, a identificação dos gatilhos que conduzem ao seu surgimento e posterior desenvolvimento faz parte do mapeamento da situação anterior, conforme Maurer e Silva (2015), de modo que o pesquisador descobre as disfunções nas práticas correntes sob a ótica dos atores envolvidos na dinâmica de mudança das práticas. Ao mesmo tempo, é comum o entendimento (PHILLIPS, LEE, JAMES et al., 2015; CORREIA, OLIVEIRA e GOMEZ, 2016) de que a aprendizagem coletiva é o que pavimenta o caminho para o desenvolvimento das inovações.

Por conseguinte, torna-se lógico que o surgimento de novas práticas ocorre por meio das interações entre os atores sociais, que, embebidas de elementos extremamente tácitos e simbólicos, reconfiguram as práticas estabelecidas (BISPO, 2013; CORREIA, OLIVEIRA e GOMEZ, 2016). Howaldt, Kopp e Schwarz (2015) argumentam que essa mudança ocorre com a repetição de rotinas cotidianas que são modificadas sutilmente ao longo do tempo até o estabelecimento da nova prática. Assim sendo, frisamos a importância de valorizar o contexto (HOWALDT e SCHWARZ, 2010; CAJAIBA-SANTANA, 2014) e compreender os significados e sentidos compartilhados pelo grupo para obter maior clareza na análise da dinâmica de mudança das práticas.

As organizações podem exercer diferentes papéis no desenvolvimento das inovações sociais (CORREIA, OLIVEIRA e GOMEZ, 2016). Segundo Lyon (2012), podem existir relações verticais, em que determinado participante atua em virtude da sua influência e poder na sustentação econômica do que se propôs, como também as horizontais, em que há compartilhamento de conhecimentos e ferramentas, de modo que os atores se percebem de maneira mais equitativa. A este respeito, Chalmers (2012) chama a atenção para a importância de se cultivar uma rede colaborativa, na qual os parceiros atuam de maneira conjunta, estabelecendo ações integradas.

Assemelhando-se à perspectiva da inovação aberta, as trocas entre ambiente interno e externo são mais frutíferas no desenvolvimento de inovações sociais (CHALMERS, 2012; CORREIA, OLIVEIRA e GOMEZ, 2016; SILVA e BITENCOURT, 2016). Ademais, a prática de inovação social só é bem sucedida quando socialmente aceita, isto é, legitimada no contexto em questão. Diante disso, a continuidade das ações em consequência da receptividade dos envolvidos à mudança é o que consolida a nova prática (HOWALDT, KOPP e SCHWARZ, 2015; MAURER e SILVA, 2015). Nesse processo, os próprios atores sociais podem sofrer transformações no que se refere a atitudes, comportamentos e percepções (CORREIA, OLIVEIRA e GOMEZ, 2016). Por esse motivo, a investigação das atividades realizadas e também das interações entre os atores é uma condição necessária à compreensão da dinâmica de mudança das práticas. 


\section{DESDOBRAMENTOS METODOLÓGICOS}

Partindo-se do pressuposto de que a realidade é socialmente construída e da necessidade de considerar o contexto nas investigações, adotamos a etnometodologia garfinkeliana como método de pesquisa. Esta abordagem dá atenção aos compartilhamentos de significados entre as pessoas em suas práticas cotidianas, além de permitir o estudo das formas de organizar dos envolvidos no processo de inovação social por intermédio de sua própria ótica (ADAMOGLU DE OLIVEIRA e MONTENEGRO, 2012; BISPO e GODOY, 2014).

Para a execução da pesquisa, em primeiro lugar, realizamos uma revisão de literatura utilizando as bases de dados Scopus e Scielo, em razão de sua relevância e interdisciplinaridade, além da inclusão de publicações de autores brasileiros. Foram também considerados os estudos de organizações e centros de pesquisa, conforme sugerem Tranfield, Denyer e Smart (2003). Adotou-se como critério de seleção considerar apenas artigos de periódicos revistos por pares e que discutissem conceitos ou modelos de análise, gestão ou mensuração da inovação social. Mediante a exclusão dos artigos em desalinho com este direcionamento, a amostra se constituiu de 44 publicações.

Uma vez definida nossa perspectiva teórica a respeito do tema, procuramos selecionar um caso em que: (1) houvesse um contexto de desenvolvimento local, cujos problemas e desafios sociais fossem nítidos; (2) existisse mais de um ator participando do processo de inovação social; e (3) as interações entre estes atores intencionassem reconfigurações na forma como os objetivos sociais são alcançados.

Mediante os critérios supracitados, selecionamos uma OSC que funciona desde $1985 \mathrm{com}$ a missão de contribuir para a efetivação dos direitos humanos, em especial crianças e adolescentes em vulnerabilidade social, com ações de educação integral, articulação comunitária e institucional e intervenção nos espaços de políticas públicas em seu estado, numa perspectiva de desenvolvimento sustentável.

Dentre suas atividades, destacam-se a promoção de oficinas pedagógicas a crianças e adolescentes, campanhas de mobilização social e a participação e intervenção nos espaços de discussão, formulação e controle de políticas públicas para crianças e adolescentes (conselhos, fóruns e redes). Ao longo dos anos, mais de 3.500 crianças e adolescentes já foram assistidas e, anualmente, mais de 170 delas são capacitadas em saúde, sexualidade e cidadania. Isso foi possível também devido à construção de uma forte rede de parceiros que viabilizam e apoiam suas ações.

Para identificarmos a inovação social a ser pesquisada, praticamos a indiferença etnomedológica, isto é, inserimo-nos no campo sem definições preestabelecidas sobre o que se deveria estudar (BISPO e GODOY, 2014). Assim sendo, decidimos pesquisar o empoderamento como exemplo de prática de inovação social, entendendo que este traz mudanças significativas à vida dos educandos e também contribui para o fortalecimento da imagem da OSC na sociedade. Para nos certificarmos de que a prática selecionada realmente se tratava de uma inovação social, confirmamos que o empoderamento era percebido como novo pelas crianças e adolescentes, fomentava uma mudança social e partia de ações coletivas e intencionais (CAJAIBASANTANA, 2014). Ao analisar uma situação anterior e outra posterior no contexto estudado (HOWALDT, KOPP e SCHWARZ, 2015; MAURER e SILVA, 2015), percebemos que a prática foi responsável por impactos positivos, com base nos resultados documentados pela própria OSC e nas percepções dos indivíduos beneficiados.

Diante disso, tendo selecionado a nova prática gerada com vistas à mudança social (CAJAIBA-SANTANA, 2014; HOWALDT, KOPP e SCHWARZ, 2015), pudemos perceber: (1) quais atores estavam envolvidos no desenvolvimento dessa prática, compondo a rede de inovação social e, portanto, o contexto de pesquisa (BISPO, 2013; SILVA e BITENCOURT, 2016; AGOSTINI, VIEIRA, TONDOLO et al., 2017) e (2) a mudança no contexto pela análise de uma situação anterior e outra posterior (HOWALDT, KOPP e SCHWARZ, 2015; MAURER e SILVA, 2015), configurando uma perspectiva longitudinal, que, por sua vez, favoreceu o entendimento das inovações em seu contexto histórico-cultural (AYOB, TEASDALE e FAGAN, 2016).

A coleta de dados foi realizada entre os meses de maio e novembro de 2017 e foram adotadas observações participantes, entrevistas não estruturadas, fotos, análise de documentos e gravações em áudio e vídeo. Os resultados das interações diárias com os integrantes da OSC em reuniões, eventos e oficinas foram registrados em um bloco de notas. Entre os documentos analisados, destacamos o planejamento estratégico, plano de metas, estatuto, plano de captação de recursos, organograma, relatórios de projetos ativos, planilhas de monitoramento dos educadores e dos educandos. 
As fotos e gravações foram úteis para consulta constante dos momentos em que os educandos se apresentavam ou se expressavam em eventos ou atividades das oficinas, auxiliando a recordar da manifestação da prática de inovação social identificada. As entrevistas foram realizadas com coordenadores administrativo e pedagógico, educadores, assistente social, educandos e ex-educandos. O número de sujeitos pesquisados dependeu tanto da quantidade de organizações envolvidas quanto da saturação dos dados, tendo sido realizadas 18 entrevistas.

A análise dos dados ocorreu de maneira interpretativa visando à compreensão dos significados compartilhados entre os indivíduos, de modo que a chave, sob uma perspectiva etnometodológica, é estar seguro de que os sentidos atribuídos às interpretações representam a realidade vivida no contexto estudado (TEN HAVE, 2004). Para isso, utilizamos os cinco conceitoschaves da etnometodologia garfinkeliana descritos em Bispo e Godoy (2014) como orientação para averiguar as características associadas a cada conceito-chave (Quadro 1), pois estes contemplam as características centrais dessa abordagem.

Quadro 1

Análise e Interpretação de Dados Etnometodológicos

\begin{tabular}{|c|c|c|}
\hline Conceito & Descrição Teórica do Conceito & $\begin{array}{l}\text { Pergunta de Orientação Analítica e } \\
\text { Interpretativa }\end{array}$ \\
\hline Prática / Realização & $\begin{array}{l}\text { Indica a experiência e a realização da } \\
\text { prática dos membros de um grupo em } \\
\text { seu contexto cotidiano, ou seja, é preciso } \\
\text { compartilhar desse cotidiano e do contexto } \\
\text { para que seja possível a compreensão das } \\
\text { práticas do grupo. }\end{array}$ & $\begin{array}{l}\text { As atividades identificadas representam o } \\
\text { cotidiano da organização/grupo investigado } \\
\text { e são reconhecidas pelos seus membros } \\
\text { como próprias e características da } \\
\text { organização/grupo ao qual pertencem? }\end{array}$ \\
\hline Indicialidade & $\begin{array}{l}\text { Refere-se a todas as circunstâncias que uma } \\
\text { palavra carrega em uma situação. Tal termo } \\
\text { é adotado da linguística e denota que ao } \\
\text { mesmo tempo em que uma palavra tem } \\
\text { um significado de algum modo "genérico", } \\
\text { esta mesma palavra possui significação } \\
\text { distinta em situações particulares. Assim, } \\
\text { a sua compreensão, em alguns casos, } \\
\text { necessita que as pessoas busquem } \\
\text { informações adicionais que vão além do } \\
\text { simples entendimento genérico da palavra. } \\
\text { Trata-se da linguagem em uso. }\end{array}$ & $\begin{array}{c}\text { O conjunto de atividades identificadas } \\
\text { apresenta uma linguagem própria da } \\
\text { organização/grupo investigado em que } \\
\text { todos os membros compartilham dela e } \\
\text { do (s) sentido (s) que ela representa na } \\
\text { vida cotidiana dessa organização/grupo? } \\
\text { É possível identificar jargões e/ou palavras } \\
\text { próprias? }\end{array}$ \\
\hline Reflexividade & $\begin{array}{l}\text { Está relacionada aos "efeitos" das práticas } \\
\text { de um grupo, trata-se de um processo em } \\
\text { que ocorre uma ação e, ao mesmo tempo, } \\
\text { produz uma reação sobre os seus criadores. }\end{array}$ & $\begin{array}{l}\text { O conjunto de atividades identificadas cria } \\
\text { ao longo do tempo na organização/grupo } \\
\text { condições de perpetuação, modificação } \\
\text { ou até mesmo geram novas atividades que } \\
\text { são reconhecidas pelos membros como } \\
\text { resultado do seu cotidiano? }\end{array}$ \\
\hline Relatabilidade & $\begin{array}{l}\text { É como o grupo estudado descreve as } \\
\text { atividades práticas a partir das referências } \\
\text { de sentido e significado que o próprio } \\
\text { grupo possui. Pode ser considerada } \\
\text { como uma "justificativa" do grupo para } \\
\text { determinada atividade e conduta. }\end{array}$ & $\begin{array}{l}\text { É possível identificar nas falas e ações dos } \\
\text { membros da organização/grupo justificativa } \\
\text { comum para orientar a razão pela qual o } \\
\text { conjunto de atividades é realizado daquela } \\
\text { forma e não de outra? }\end{array}$ \\
\hline Noção de Membro & $\begin{array}{c}\text { O membro é aquele que compartilha da } \\
\text { linguagem de um grupo, induz a uma } \\
\text { condição de "ser" do e no grupo e não } \\
\text { apenas de "estar". }\end{array}$ & $\begin{array}{l}\text { O conjunto de atividades mapeadas } \\
\text { permite ao pesquisador identificar } \\
\text { claramente quem são os indivíduos que } \\
\text { são efetivamente da organização/grupo e } \\
\text { não apenas "estão" nele? A indicialidade e } \\
\text { a relatabilidade são fundamentais para tal } \\
\text { reconhecimento. }\end{array}$ \\
\hline
\end{tabular}

Fonte: Bispo e Godoy (2014). 
Ademais, visando ao rigor metodológico, valorizamos a triangulação dos dados (por meio das diversas técnicas de coleta de dados utilizadas), a descrição clara, rica e detalhada dos procedimentos metodológicos, a reflexividade e abertura a evidências que estimulassem novas formas de pensamento sobre o tema (por intermédio da indiferença etnometodológica e percepção da realidade como socialmente construída) (PAIVA JÚNIOR, LEÃO e MELLO, 2011).

\section{Discussão dos Resultados}

Esta seção está dividida em três subseções. Na primeira discutimos o contexto, os gatilhos que levam a uma mudança social e os impactos das ações da OSC sobre as crianças e adolescentes atendidos. A segunda subseção apresenta as atividades que compõem a prática da inovação social. A última subseção descreve os atores envolvidos.

\section{Contexto, gatilhos e impactos}

A OSC estudada situa-se na Zona Norte da capital de um estado nordestino, em um bairro em que se encontram as maiores concentrações de indivíduos de camadas economicamente desfavorecidas e altos índices de exclusão, caracterizando uma situação de alta vulnerabilidade social e estigmas fortalecidos pela mídia (vide Figura 1). Durante caminhadas com integrantes da OSC pelo bairro, observações e conversas informais, verificamos como esta realidade se apresenta nas vidas das famílias que moram nestes locais, em especial das crianças e adolescentes matriculados na OSC. Por exemplo: não é raro que os alunos sejam vizinhos de traficantes de drogas e assassinos de aluguel, ou mesmo que seus pais, irmãos ou quaisquer parentes estejam envolvidos com substâncias ilícitas ou nas disputas entre gangues.

Alguns alunos são até mesmo filhos de chefes do tráfico, presidiários e matadores. Ao mesmo tempo, também não é difícil encontrar crianças e adolescentes temerosos, que não andam em determinadas ruas porque estas pertencem a facções criminosas rivais às existentes em sua própria comunidade. Por meio de frequentes conversas com educadores, funcionários da equipe de apoio e também participando de reuniões na OSC, tomamos conhecimento de que muitas crianças e adolescentes frequentam as atividades com fome e sujas. Também nos informaram que não ter o que comer e vestir, assim como dinheiro para reverter esta situação, não é incomum, confirmando a realidade observada durante as caminhadas.

Figura 1

\section{Condições de Vida nas Comunidades}

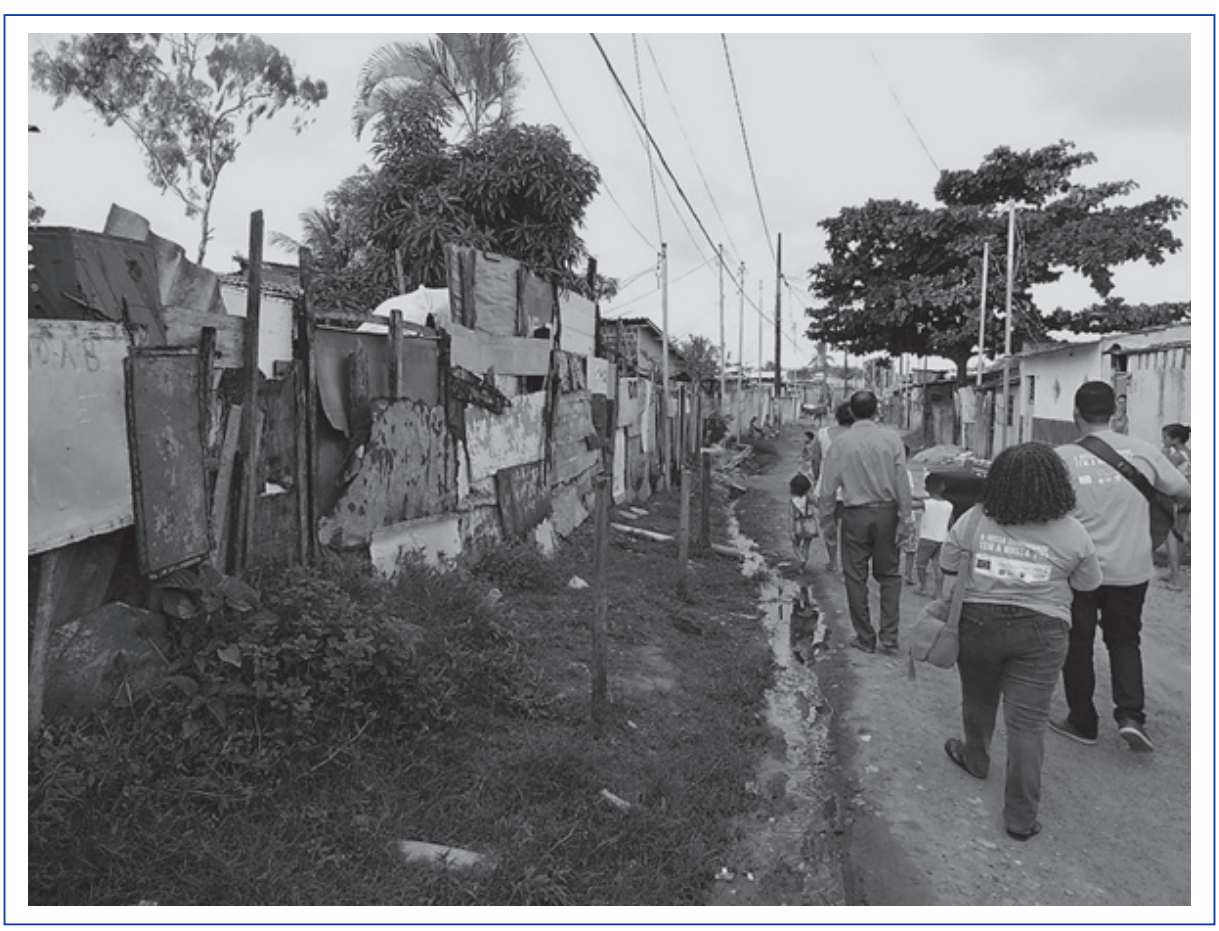

Fonte: Arquivo da OSC (2018). 
Outro ponto é o baixo grau de instrução dos chefes de família, o que também dificulta o acesso a empregos e pode impactar no desenvolvimento das crianças e adolescentes. Por exemplo: uma das mães revelou que sofria violência sexual e agredia seus filhos, pois Ihe faltava direcionamento. Contudo, contou que, depois de matriculá-los na OSC, passar a frequentar as oficinas profissionalizantes oferecidas a ela e as reuniões de familiares, aprendeu como poderia ser uma mãe mais carinhosa, atenciosa e educá-los sem a necessidade de violência. A propósito, um dos educadores contava-nos que, diante das rejeições e abandonos sofridos pelas crianças e adolescentes, a inserção no tráfico de drogas como "aviãozinho" (crianças que abordam potenciais clientes para venda) se apresentava como uma alternativa tentadora por acolhê-los e prometer ganhos financeiros.

Nessa conjuntura, conforme destacam Murray, Mulgan e Caulier-Grice (2008) e Cajaiba-Santana (2014), inovações sociais são iniciativas favoráveis no intuito de minimizar os efeitos negativos ocasionados pela vulnerabilidade social. Isso porque o crescente número de problemas sociais, econômicos e ambientais impulsiona a necessidade de desenvolver novas formas de tratá-los e/ou eliminá-los, visando à mudança social por meio da reconfiguração de como os objetivos são alcançados. Percebemos, portanto, que os gatilhos que apontaram a necessidade de mudança foram a violência e pobreza, o tráfico de drogas e os estigmas associados ao bairro. Logo, identificamos que a prática do empoderamento como inovação social emerge em virtude da própria situação de vulnerabilidade social na qual as crianças e os adolescentes estão imersos. Ou seja, em virtude das dificuldades e barreiras associadas à exclusão social, em alinhamento com Howaldt, Kopp e Schwarz (2015), o empoderamento surge como alternativa para suavizar e/ou reverter essas desigualdades.

Destarte, a OSC pesquisada aparece como um espaço de convivência comunitária, sendo reconhecida no bairro pelas atividades empreendidas. Suas ações estão em conformidade com a percepção da European Commission (2013) de que o empoderamento por meio da educação pode ser um meio de resposta à exclusão social. Ao longo dos últimos 32 anos, mais de dez mil crianças, adolescentes e jovens até 24 anos participaram das atividades oferecidas pela OSC, o que contribui para seu desenvolvimento físico, psíquico e social, bem como para a mobilização de melhorias na comunidade. São exemplos do sucesso das ações da OSC a diminuição de casos de violação dos direitos, a maior inserção dos jovens no mercado de trabalho e suas participações em apresentações culturais e artísticas, além do acesso a cursos de extensão ou atividades extracurriculares associadas à potencialidade identificada nas oficinas promovidas pela Organização.

Muitos ex-alunos, seus familiares e funcionários antigos da OSC explicaram-nos como as pessoas que têm acesso às atividades conseguem vislumbrar outras possibilidades e meios de vida que vão na contramão do que configura o status quo das comunidades em situação de vulnerabilidade. Conseguem sonhar e se sentir capazes de realizar esses sonhos, não cedendo aos convites do tráfico de drogas ou às desesperanças que a exclusão social produz, por exemplo. A propósito, alguns adolescentes relataramnos que sua maneira de enxergar o mundo e de tomar decisões é constantemente lapidada em virtude do conhecimento que eles acessam por intermédio das atividades proporcionadas pela OSC. Tais depoimentos são também corroborados por ex-alunos que, por sua vez, já se encontram vivenciando as experiências e oportunidades que sonharam outrora.

Ademais, na análise documental, tivemos acesso a um estudo realizado pela OSC com um de seus parceiros que buscou aferir o impacto, no longo prazo, das atividades de atendimento direto na vida das crianças e adolescentes tomando por referência os anos de 2002 a 2012, denominado "Estudo de Impacto". Destacamos o resultado encontrado de que há uma disparidade no nível de educação entre as crianças e adolescentes que frequentam a OSC e as que não frequentam. Nas comunidades atendidas, que são marcadas pela alta vulnerabilidade social, aqueles que participaram das oficinas tinham um nível educacional mais elevado. Assim, muitos ex-educandos chegaram a concluir o ensino universitário, técnico e médio, enquanto nestes bairros é comum a educação básica incompleta entre as pessoas.

Além disso, os efeitos da inovação social se estendem para além do nível de autonomia pessoal, pois essas pessoas tornam-se também multiplicadores do conhecimento adquirido. Isso ocorre porque, com as discussões dos temas mensais, eles se apropriam de informações que podem ajudá-los não só a se proteger e exercer seus direitos, mas também auxiliar amigos e sua própria família. Por exemplo: uma das educandas contou que, tendo aprendido e conversado sobre bullying e suas consequências nas oficinas da OSC, sentia-se apta e à vontade para ensinar seus amigos quando eles praticassem alguma atitude desrespeitosa. Além disso, também foi registrado no "Estudo de Impacto" (documento interno) que a multiplicação dos aprendizados se estende para o convívio familiar. Nas subseções seguintes, descrevemos as atividades e atores que viabilizaram estas conquistas. 


\section{Atividades que compõem a prática da inovação social}

Compreendemos que as iniciativas realizadas pela OSC contribuem para o desenvolvimento de inovações sociais. Em vista disso, verificamos que as inovações facilitadas pela OSC alinham-se a uma perspectiva mais orientada ao processo, pois buscam transformar as práticas que ocasionam as desigualdades sociais e, dessa forma, ensinam a pescar. Verificamos que as oficinas promovidas pela OSC são as maiores responsáveis pelo desenvolvimento da prática de empoderamento de crianças e adolescentes. Nesse sentido, é importante destacar que as oficinas são as ações de atendimento direto às crianças e adolescentes, objetivando a formação cidadã por intermédio de atividades culturais, pedagógicas e esportivas. Dentre as diferentes oficinas já ofertadas pela OSC estão: artes visuais, dança, canto, ioga, contação de histórias, teatro, protagonismo juvenil, futebol, flauta, metais e música. Os inscritos em cada oficina participam de aulas com carga horária variada que contemplam tanto o desenvolvimento na técnica específica da oficina como a discussão dos chamados temas transversais, por exemplo: trabalho infantil, sexualidade, saúde e higiene. Importante, ainda, salientar que os educandos podem participar de mais de uma oficina.

Os educandos são bastante incentivados a se desenvolverem, seja em aspectos mais subjetivos como a superação de uma timidez ou a busca por uma vocação profissional, ou aspectos mais técnicos, como a evolução com instrumentos musicais ou na dança e artes visuais. Uma vez que são cobrados por este desenvolvimento, os educadores devem fornecer à coordenação pedagógica relatórios mensais em que constam os conteúdos abordados, seus objetivos, atividades planejadas, materiais necessários e os resultados alcançados. Tais relatórios permitem o acompanhamento dos objetivos estratégicos e subsidiam as ações da OSC, além de constituírem outros relatórios que são enviados aos financiadores como feedback dos seus investimentos em projetos sociais, configurando o que chamam de "dinâmica da casa". Além de constarem em relatórios, os resultados são percebidos pela própria comunidade e sociedade ao longo do ano em eventos promovidos, que contam com a participação das crianças e adolescentes.

Anualmente, a OSC também realiza um diagnóstico em que são mapeadas as problemáticas latentes do bairro e as inquietações das crianças e adolescentes. Com base nos resultados, são estabelecidos, no planejamento anual, os temas transversais a serem discutidos nas oficinas. Assim, se um educador descobrir que existe um caso de violência doméstica ocorrendo com algum de seus educandos, por exemplo, além de encaminhar essa situação ao setor psicossocial (setor da OSC responsável pelo acompanhamento das crianças, adolescentes e suas famílias), ele pode tornar a discutir o tema em sua oficina. Em entrevista, uma adolescente explicou que discutir estes temas a ajudava a "abrir a cabeça" e, ao entender seus direitos, sentia-se mais apta a se expressar na busca pela garantia deles, conquistando seu espaço.

Com base nisso, percebemos que as crianças e adolescentes se sentem cada vez mais confortáveis para comunicar suas necessidades por meio da sondagem, mas também ao longo das oficinas, atuando, em consonância com Iwamoto e Cançado (2016) e Montgomery (2016), como cocriadores e até modelando as ações da OSC.

$\mathrm{Na}$ oficina de artes, por exemplo, uma das adolescentes contava que se sentia muito sozinha e sua mãe não era atenciosa. Com este relato, a educadora encaminhou sua situação ao setor psicossocial e passou a incentivar sua matrícula em mais oficinas, como também sua maior participação em atividades em grupo. Na oficina de dança de determinado ano, o enfoque das aulas foi o balé clássico, por ser o estilo que os educandos mais gostariam de aprender, e uma vez que isso foi informado à educadora, observou-se que era exequível. Compreendemos, então, que as mudanças na prática ocorrem por meio da comunicação e mapeamento das necessidades dos participantes e do bairro juntamente com a análise da viabilidade por parte da OSC, de acordo com seus recursos. Ao mesmo tempo, a disponibilidade de recursos financeiros e de pessoal são aspectos limitantes para o desenvolvimento de determinadas atividades planejadas.

Em conversa com os educadores e coordenadores da OSC, eles nos relataram o quanto a observação das crianças e adolescentes durante as oficinas era importante, pois, além de direcionar a atuação do educador em sala, ajuda a perceber os sinais de violações dos direitos. Quando um aluno, por exemplo, começa a demonstrar um comportamento agressivo, diferente do usual, o educador já se atenta para verificar o que está acontecendo e tomar as providências necessárias. De outra parte, reconhecemos que o trabalho dos educadores pode ser refinado, potencializando os efeitos da prática, pela maior dedicação à reflexão de suas atitudes e comportamentos que, por vezes, chocam-se com o posicionamento filosófico da OSC.

Em virtude dessa maior participação dos educandos, eles se tornam menos dependentes das ações de agentes externos e têm seu senso de poder pessoal fortalecido, uma vez que as mudanças os desenvolvem enquanto seres humanos, o que torna a inovação social mais duradoura. Por conseguinte, como destacam Correia, Oliveira e Gomez (2016), a contínua interação 
entre educador e educando também leva ao empoderamento e consequente mudanças de atitude, comportamento e percepção dos educandos. É importante salientar que, enquanto crianças e adolescentes, eles possuem uma condição de dependência natural, porém aqui tratamos o empoderamento como um processo de busca pela autonomia na descoberta por suas potencialidades, não como uma independência associada à vida adulta (financeira, emocional e mental). Logo, o empoderamento apresenta-se, principalmente, com o aumento da autoconfiança e autopercepção por parte de um sujeito de direitos que tem oportunidades e capacidade de realização.

Desse modo, é importante destacar o quanto a prática de empoderamento é exercida de maneira diferente por cada educando. Enquanto existem algumas crianças e adolescentes que apresentam significativas dificuldades emocionais ou físicas que comprometem sua participação integral e sadia nas oficinas, há outras que se sentem bastante autoconfiantes e demonstram um desenvolvimento pessoal e técnico relevante. Assim, esses aspectos são percebidos pelos educadores durante as aulas e é desta observação contínua que eles compreendem a evolução dos seus alunos e a registram em seus relatórios ou realizam os encaminhamentos necessários, como também direcionam o planejamento e a execução de suas oficinas.

De acordo com o exposto, os educandos mais empoderados conseguem se dedicar melhor e apresentar avanços na aprendizagem da técnica e na compreensão e discussão dos temas transversais. Os educadores, de forma unânime, relataram diversas vezes o quanto eles respeitam o limite de cada aluno e entendem que o tempo de aprendizado não é igual para todos. Ao mesmo tempo, observamos, em diversas ocasiões, os educadores dando atenção mais demorada aos alunos que apresentavam maior dificuldade ou mesmo incentivando aqueles que possuem conhecimentos mais avançados a auxiliarem os outros. É comum, por exemplo, nas oficinas de dança as "bambinas" - termo usado pela educadora para chamar as educandas à aula - que mais dominam as técnicas auxiliarem suas colegas na assimilação dos movimentos coreográficos.

Diante disso, compreendemos que as atitudes, comportamentos e ações das crianças e adolescentes em seu cotidiano são os meios de materialização da prática de empoderamento. Desse modo, é seguro dizer que as formas que esta prática assume são mais intangíveis, sendo viabilizadas por meio de espaços participativos favorecidos pelos adultos nas oficinas ofertadas pela OSC, de eventos e reuniões que as crianças e adolescentes são convidados a participar ou se apresentar. Por sua forma envolver um conjunto de ações e atitudes características de um grupo, os resultados se tornam mais difíceis de difundir. Afinal, como assevera Bispo (2013), as práticas são tácitas e simbólicas em grande medida, corroborando diversos autores (HOWALDT e SCHWARZ, 2010; CAJAIBA-SANTANA, 2014) no que se refere ao aspecto dependente do contexto das inovações sociais. Na subseção a seguir apresentamos outros atores que também contribuem para o desenvolvimento da prática.

\section{Atores}

As inovações se desenvolvem por meio da colaboração entre diversos atores que, juntos, constituem uma rede de inovação social, conforme Tanimoto (2012), Phillips, Lee, James et al. (2015) e Silva e Bitencourt (2016). Por essa razão, foi necessário identificar quais dos parceiros da OSC atuavam no desenvolvimento da prática de empoderamento, tendo como recorte de análise aqueles que apoiavam de alguma forma as ações de atendimento direto empreendidas no bairro. Para tanto, em nossas visitas, conversamos com os funcionários para entender quais eram os órgãos que ouvíamos citarem nas reuniões, os seus papéis nas atividades da OSC e como funcionava seu processo de trabalho. Além disso, também tivemos acesso aos relatórios dos projetos ativos e organograma de parceiros, o que nos auxiliou na identificação dos atores relacionados à prática.

Sendo assim, os atores envolvidos no processo que constituem a rede de inovação social são: a OSC, as escolas do bairro, as crianças e adolescentes matriculadas nas oficinas, a Fundação San Zeno, o Itaú Social, a Organização das Nações Unidas para a Educação, a Ciência e a Cultura (UNESCO), a Rede de Proteção à Criança e ao Adolescente do bairro, a Rede de Proteção Estadual e o Conselho Consultivo da Criança e Adolescente do município estudado. A prática de inovação social, em conformidade com Howaldt, Kopp e Schwarz (2015) e Maurer e Silva (2015), consolida-se pela continuidade das ações e aprendizagem coletiva oriundas das interações entre os referidos atores. Estes têm participado de maneira mais ou menos ativa no incentivo ao empoderamento das crianças e adolescentes, isto é, com maior ou menor frequência de envolvimento, físico ou virtual, no desenvolvimento de atividades com este objetivo. Essas relações podem ser visualizadas na Figura 2 a seguir. 
Figura 2

Participação dos Atores Sociais

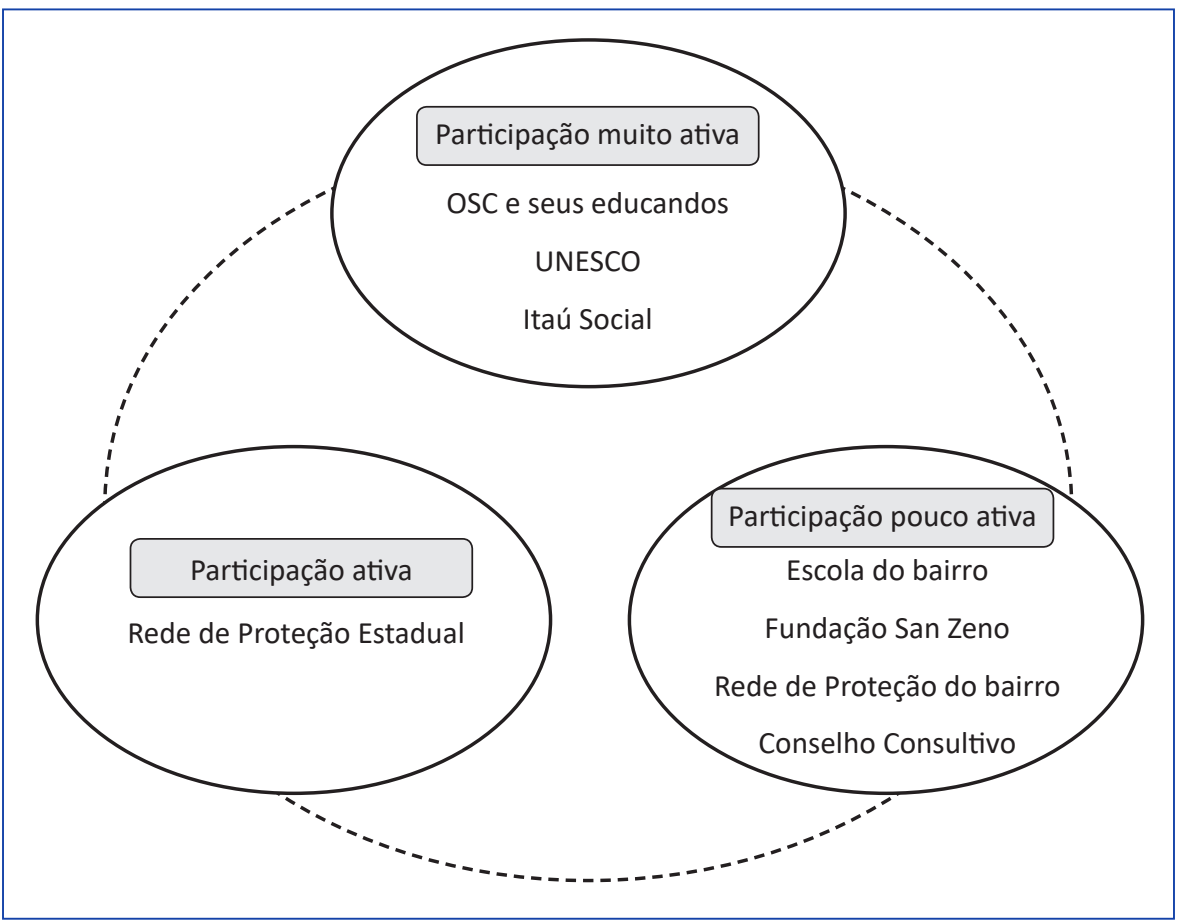

Fonte: Elaborada pelos autores (2018).

Justificamos que a OSC e seus educandos possuem participação muito ativa em virtude do seu envolvimento direto e contínuo nas oficinas realizadas. O mesmo é válido para os parceiros Itaú Social e UNESCO, por estes subsidiarem financeiramente todas as ações de atendimento direto realizadas cotidianamente pela OSC e, assim, acompanharem em maior amplitude as ações empreendidas. Da parte da fundação San Zeno é feito o financiamento de apenas uma das oficinas; portanto classificamos como uma participação pouco ativa. A Rede de Proteção à Criança e ao Adolescente de atuação local e o Conselho Consultivo do município possuem participação pouco ativa no desenvolvimento do empoderamento: viabilizam mensalmente um espaço de discussão entre as crianças e adolescentes em situação de vulnerabilidade social e adultos que podem auxiliar na mudança desta realidade.

O mesmo ocorre com a Rede de Proteção Estadual, porém esta rede também forneceu bastante suporte para o fechamento da parceria com a fundação San Zeno, o que nos leva a julgar sua participação como ativa. As escolas do bairro possuem participação pouco ativa: contribuem anualmente com o preenchimento de um documento denominado "mapa escolar". Nele as escolas informam a situação escolar (desempenho e frequência nas aulas) dos educandos da OSC que lá estudam. Por fim, entende-se, conjuntamente com Lyon (2012), que as relações entre estes atores são horizontais e o compartilhamento de conhecimentos e ferramentas é predominante, constituindo uma rede colaborativa (CHALMERS, 2012). 


\section{CONCLUSÕES}

Os resultados desta pesquisa contribuem para o avanço do conhecimento sobre a temática de inovação social de diversas maneiras diferentes. Primeiro, pelos esforços em trazer maior clareza conceitual e robustez da perspectiva teórica por meio da compreensão da inovação social como prática, conforme lacuna apontada por Howaldt, Domanski e Kaletka (2016) e Van der Have e Rubalcaba (2016). Segundo, por ampliar os incipientes estudos brasileiros sobre a temática, como sugere Agostini, Vieira, Tondolo et al. (2017), e por ser realizada em um locus com nítidos problemas e desafios sociais, conforme oportunidade de pesquisa sugerida por Iwamoto e Cançado (2016). Terceiro, a investigação de como cada ator atua no desenvolvimento das inovações lança luz a respeito do processo de inovação social, contribuindo para o entendimento da dinâmica de mudança da prática e sua legitimação no contexto estudado, conforme lacunas identificadas por Grimm, Fox, Baines et al. (2013), Howaldt, Kopp e Schwarz (2015), Agostini, Vieira, Tondolo et al. (2017) e Silveira e Zilber (2017).

Além disso, os resultados também são úteis ao desenvolvimento do campo de estudos por analisar longitudinalmente as inovações e seus efeitos em uma perspectiva comparativa de uma situação anterior e outra posterior em um dado contexto, conforme lacunas de pesquisa apontadas por Maurer e Silva (2015) e Ayob, Teasdale e Fagan (2016). Em complemento, contribui por evidenciar como ocorre a ampliação do empoderamento das pessoas, atendendo a uma sugestão de pesquisa de Iwamoto e Cançado (2016).

Do ponto de vista metodológico, este artigo contribui por se basear na etnometodologia garfinkeliana, que permite o entendimento da dinâmica de mudança da prática em uma perspectiva mais interpretativista, além do fato de não terem sido encontrados estudos anteriores que utilizassem esta abordagem na investigação empírica de práticas de inovação social.

Do ponto de vista prático, os achados da pesquisa fornecem insights aos integrantes da OSC e aos demais participantes da rede de inovação social por trazer um panorama do seu status quo, fornecendo subsídios às resoluções de problemas, decisões estratégicas e operacionais. Também estimulam a difusão das práticas de inovação social em outros domínios, uma vez que as inovações bem-sucedidas, conforme Phillips, Lee, James et al. (2015), são úteis aos legisladores com o intuito de produzir resultados sustentados, apropriados e relevantes às organizações e sociedade. Logo, este artigo pode ser útil à criação de políticas públicas ou mesmo à aproximação com as instituições públicas, incentivando o fortalecimento da parceria entre os setores, como apontam Phillips, Lee, James et al. (2015) e Pelka e Terstriep (2016).

Algumas inquietações sobre a temática persistem e podem ser desenvolvidas em pesquisas futuras, por exemplo: como são desenvolvidas inovações sociais em um estrato mais favorecido da sociedade? Como ocorre a legitimação da prática em um contexto em que há pouca ou nenhuma participação ativa do grupo-alvo no processo? Quais as principais diferenças entre uma mesma prática de inovação social que é difundida para outros contextos? Como ocorrem as interações da rede de inovação social considerando os elementos não humanos da prática? 


\section{REFERÊNCIAS}

ADAMOGLU DE OLIVEIRA, S. A.; MONTENEGRO, L. M. Etnometodologia: desvelando a alquimia da vivência cotidiana. Cadernos EBAPE.BR, Rio de Janeiro, v. 10, n. 1, p. 129-145, 2012.

AGOSTINI, M. et al. An overview on social innovation research: guiding future studies. Brazilian Business Review, v. 14, n. 4, p. 385-402, 2017.

ANDRÉ, I.; ABREU, A. Dimensões e espaços da inovação social. Revista portuguesa de geografia, Finisterra, v. 41, n. 81, p. 121-141, 2006.

AYOB, N.; TEASDALE, S.; FAGAN, K. How Social Innovation 'Came to Be': tracing the Evolution of a Contested Concept. Journal of Social Policy, v. 45, n. 4, p. 635-653, 2016.

BISPO, M. Estudos Baseados em Prática: Conceitos, História e Perspectivas. Revista Interdisciplinar de Gestão Social, v. 2, n. 1, p. 13-33, 2013.

BISPO, M. S.; GODOY, A. S. Etnometodologia: uma Proposta para Pesquisa em Estudos Organizacionais. Revista de Administração da UNIMEP, v. 12, n. 2, p. 108-135, 2014.

CAJAIBA-SANTANA, G. Social innovation: moving the field forward. A conceptual framework. Technological Forecasting and Social Change, v. 82, p. 42-51, 2014.

CHALMERS, D. Social innovation: an exploration of the barriers faced by innovating organizations in the social economy. Local Economy, v. 28, n. 1, p. 17-34, 2012.

CORREIA, S. E. N.; OLIVEIRA, V.; GOMEZ, C. R. P. Dimensions of social innovation and the roles of organizational actor: the proposition of a framework. RAM - Revista de Administração Mackenzie, v. 17, n. 6, p. 102-133, 2016.

COSTA, M; A.; MARGUTI, B. O. (Eds.). Atlas da vulnerabilidade social nos municípios brasileiros. Brasília: IPEA, 2015.

EUROPEAN COMMISION. Social innovation research in the European Union: approaches, findings and future directions. Policy Review. Luxembourg: Publications Office of the European Union, 2013.

FUNDAÇÃO ABRINQ. Cenário da Infância e Adolescência no Brasil 2016. São Paulo: Coktail Gráfica e Editora, 2016. Disponível em: <https://goo.gl/MV8fWy>. Acesso em: 02 ago. 2017.

GONZALEZ-MENA, J. Fundamentos da educação infantil: ensinando crianças em uma sociedade diversificada. 6. ed. Porto Alegre: AMGH, 2015.

GRIMM, R. et al. Social innovation, an answer to contemporary societal challenges? Locating the concept in theory and practice. Innovation: the European Journal of Social Science Research, v. 26, n. 4 , p. $436-455,2013$

HOWALDT, J.; DOMANSKI, D.; KALETKA, C. Social Innovation: towards a new innovation paradigm. RAM, Revista de Administração Mackenzie, v. 17, n. 6, p. 20-44, 2016.

HOWALDT, J.; KOPP, R.; SCHWARZ, M. Social Innovation as Drivers of Social Change - Exploring Tarde's Contribution to Social Innovation Theory Building. In: NICHOLLS, A.; SIMON, J.; GABRIEL, M. (Orgs.). New Frontiers in Social Innovation Research. New York: Palgrave Macmillan, 2015. p. 29-51.

HOWALDT, J.; SCHWARZ, M. Social innovation: concepts, research fields and international trends. Dortmund: Sozialforschungsstelle Dortmund, 2010.
INSTITUTO BRASILEIRO DE GEOGRAFIA E ESTATÍSTICA - IBGE. Síntese de Indicadores Sociais: uma análise das condições de vida da população brasileira: 2015. Rio de Janeiro: IBGE, 2015.

IWAMOTO, H. M.; CANÇADO, A. C. Inovação Social e Emancipação: possíveis convergências. In: ENCONTRO NACIONAL DA ASSOCIAÇÃO NACIONAL DE PÓS-GRADUAÇÃO E PESQUISA EM ADMINISTRAÇÃO, 40., 2016, Costa do Sauípe, Anais... Costa do Sauípe: ANPAD, 2016.

KLEBA, M. E.; WENDAUSEN, A. Empoderamento: processo de fortalecimento dos sujeitos nos espaços de participação social e democratização política. Saúde e Sociedade, v. 18, n. 4, p. 733743,2009

LYON, F. Social Innovation, Co-operation, and Competition: Interorganizational Relations for Social Enterprises in the Delivery of Public Services. In: NICHOLLS, A.; MURDOCK, A (Eds.). Social Innovation: Blurring Boundaries to Reconfigure Markets. New York: Palgrave Macmillan, 2012. p. 139-161.

MAURER, A. M.; SILVA; T. N. Como as Inovações Sociais criam e sustentam suas Práticas? Integrando Entendimentos de Inovação Social e Teoria de Práticas. In: ENCONTRO NACIONAL DA ASSOCIAÇÃO NACIONAL DE PÓS-GRADUAÇÃO E PESQUISA EM ADMINISTRAÇÃO, 39., 2015, Belo Horizonte. Anais... Belo Horizonte: ANPAD, 2015.

MONTGOMERY, T. Are Social Innovation Paradigms Incommensurable? Voluntas: International Journal of Voluntary and Nonprofit Organizations, v. 27, n. 4, p. 1979-2000, 2016.

MOULAERT, F. et al. Towards Alternative Model(s) of Local Innovation. Urban Studies, v. 42, n. 11, p. 1969-1990, 2005

MULGAN, G. et al. Social Innovation: what it is, why it matters and how it can be accelerated. London: The Basingstoke Press, 2007.

MURRAY, R.; MULGAN, G.; CAULIER-GRICE, J. How to Innovate: the tools for social innovation - circulated for comment. The Young Foundation Resources, 2008. Disponível em: <https://youngfoundation. org/wp-content/uploads/2012/10/How-to-innovate-the-tools-forsocial-innovation.pdf>. Acesso em: 10 nov. 2016.

PAIVA JÚNIOR, F. G.; LEÃO, A. L. M. S.; MELLO, S. C. B. Validade e confiabilidade na pesquisa qualitativa em Administração. Revista de Ciências da Administração, v. 13, n. 31, p. 190-209, 2011.

PELKA, B.; TERSTRIEP, J. Mapping Social Innovation Maps: the State of Research Practice across Europe. European Public \& Social Innovation Review, San Sebastián, v. 1, n. 1, p. 3-16, 2016.

PHILLIPS, W. et al. Social Innovation and Social Entrepreneurship: a Systematic Review. Group \& Organization Management, v. 40, n. 3, p. 428-461, 2015.

POL, E.; VILLE, S. Social innovation: Buzz word or enduring term? The Journal of Socio-Economics, v. 38, n. 6, p. 878-885, 2009.

SCHATZKI, T. R. Introduction: Practice Theory. In: SCHATZKI, T. R.; CETINA, K. K.; SAVIGNY, E. V. (Ed.). The Practice Turn In Contemporary Theory. London: Routledge, 2001, p. 10-23.

SILVA, S. B.; BITENCOURT, C. C. Rumo a um Quadro Conceitual para o Estudo de "Redes de Inovação Social". In: ENCONTRO DE ESTUDOS ORGANIZACIONAIS, 9., 2016, Belo Horizonte. Anais... Belo Horizonte: ANPAD, 2016. 
SILVEIRA, F. F.; ZILBER, S. N. Is social innovation about innovation? $A$ bibliometric study identifying the main authors, citations and co-citations over 20 years. International Journal of Entrepreneurship and Innovation Management, v. 21, n. 6, p. 459-484, 2017.

TANIMOTO, K. The emergent process of social innovation: multistakeholders perspective. International Journal of Innovation and Regional Development, v. 4, n. 3-4, p. 267-280, 2012.

TEN HAVE, P. Understanding Qualitative Research and Ethnomethodology. London: Sage, 2004.
TRANFIELD, D.; DENYER, D.; SMART, P. Towards a methodology for developing evidence informed management knowledge by means of systematic review. British Journal of Management, v. 14, n. 3, p. 207-222, 2003.

UNPD. Human Development Report. 2016. Disponível em: <https:// goo.gl/b7WR73>. Acesso em: 01 ago. 2017.

VAN DER HAVE, R. P.; RUBALCABA, L. Social innovation research: an emerging area of innovation studies? Research Policy, v. 45, n. 9, p. 1923-1935, 2016.

Thaís Teles Firmino

ORCID: https://orcid.org/0000-0002-3448-1282

Doutoranda em Administração pela Universidade Potiguar (UnP); Mestre em Administração pela Universidade Federal da Paraíba (UFPB); Professora Substituta do Departamento de Administração da Universidade Federal da Paraíba (UFPB), João Pessoa - PB, Brasil. E-mail: thaistfirmino@gmail.com

André Gustavo Carvalho Machado

ORCID: https://orcid.org/0000-0002-0589-896X

Doutor em Administração pela Universidade Federal de Pernambuco (UFPE); Professor Associado da Universidade Federal da Paraíba (UFPB), onde leciona nos cursos de graduação e pós-graduação em Administração e no Mestrado Profissional em Gestão nas Organizações Aprendentes, João Pessoa - PB, Brasil. E-mail: agcmachado@gmail.com 